\title{
Formation of InAs Nanoclusters in Silicon by High-Dose Ion Implantation: Experimental Data and Simulation Results
}

\author{
A. F. Komarov ${ }^{a}$, F. F. Komarov ${ }^{a}$, O. V. Mil’chanin ${ }^{a}$, L. A. Vlasukova ${ }^{b}$, I. N. Parkhomenko ${ }^{b}$, \\ V. V. Mikhailov ${ }^{a}$, M. A. Mokhovikov ${ }^{a}$, and S. A. Miskevich ${ }^{a}$ \\ ${ }^{a}$ Sevchenko Research Institute of Applied Physical Problems, ul. Kurchatova 7, Minsk, 220045 Belarus \\ ${ }^{b}$ Belarussian State University, pr. Nezavisimosti 4, Minsk, 220030 Belarus \\ *e-mail: KomarAF@bsu.by \\ Received July 30, 2014
}

\begin{abstract}
A physicomathematical model and dedicated software are developed for simulating high-dose implantation of two types of atoms to form InAs nanoclusters in a silicon matrix. The model is based on solving a set of convection-diffusion-reaction equations. The synthesis of InAs nanoclusters produced by highdose implantation of $\mathrm{As}^{+}$and $\mathrm{In}^{+}$ions into crystalline silicon is numerically simulated. Using the methods of transmission electron microscopy and Raman scattering, it is found that InAs nanoclusters are crystalline and have a mean diameter of $7 \mathrm{~nm}$. After As implantation $\left(170 \mathrm{keV}, 3.2 \times 10^{16} \mathrm{~cm}^{-2}\right)$ and In implantation $(250 \mathrm{keV}$, $2.8 \times 10^{16} \mathrm{~cm}^{-2}$ ) into silicon at $500^{\circ} \mathrm{C}$, the nanoclusters are distributed with a density of $2.8 \times 10^{16} \mathrm{~cm}^{-2}$. From experimental data and theoretical results, the coefficients of radiation-stimulated diffusion of In and As in silicon, as well as the fraction of the implant in the bound state (i.e., entering into InAs nanoclusters), are determined. Experimental data are compared with simulation results.
\end{abstract}

DOI: $10.1134 / \mathrm{S} 106378421509008 \mathrm{X}$

\section{INTRODUCTION}

Dopant concentration profiles obtained at lowdose implantation in the absence of chemically controlled and diffusion dopant distributions are well understood [1-3]. However, when ion fluences are high $\left(\Phi>10^{16} \mathrm{~cm}^{-2}\right)$, the dopant profile depends not only on the atomic collision kinetics but also on such processes as dopant accumulation in the target, target surface sputtering, dopant diffusion, atomic mixing, formation of new phases during implantation, and irradiation-induced swelling $[4,5]$. It is known that these processes may variously influence the profile according to experimental conditions and physicochemical properties of target and impurity atoms. This generates a need to correct the existing models $[6,7]$ and the diffusion kinetics parameters used in them $[8,9]$. In previous works of our team, the high-dose implantation of atomic and molecular nitrogen into iron [8], silicon [9], and copper [10] was studied for the case when dopant atoms chemically interact with target atoms to produce stable iron, silicon, and copper nitrides.

In general, simulation of high-dose implantation producing nanoclusters of implanted impurities is a structurally difficult problem. It is reasonable to split it into two parts. The first part consists in considering processes attendant on irradiation of the matrix by high-fluence ions and determining the fraction of implant ions that are involved in clustering. In the second part, one describes the nanocluster size distribution and its evolution upon subsequent thermal treatments. In clustering, the temperature of a test specimen during ion implantation is of key importance.

Typically, the cluster size scatter in an ionimplanted system is $20-50 \%$ [11]. The scatter is due to a nonuniform (near-Gaussian) depth distribution of the implant in the target. As a result, conditions for nucleation and clustering markedly differ on either side of a dopant concentration maximum. Such a great scatter in the cluster size is unacceptable in many applications, specifically, in optoelectronics. Therefore, gaining insight into the nucleation and growth (reconfiguration) of new-phase clusters at ion implantation, as well as the search for new ways of controlling the nanocluster size distribution, seems to be an overriding priority in the years to come [12-15].

It is known that clustering through precipitation in liquid solutions or through the Ostwald ripening in weakly supersaturated solid solutions is well described by a Gaussian size distribution, which is analytically represented by the Lifshitz-Slezof-Wagner equation [16].

At high-dose ion implantation, such an approach is valid at the early stage of implantation. In the case of long-term implantation or after thermal treatment, the behavior of the system is no longer represented with the above simple relationship. The fact is that the system gradually "loses reminiscence" of the initial 

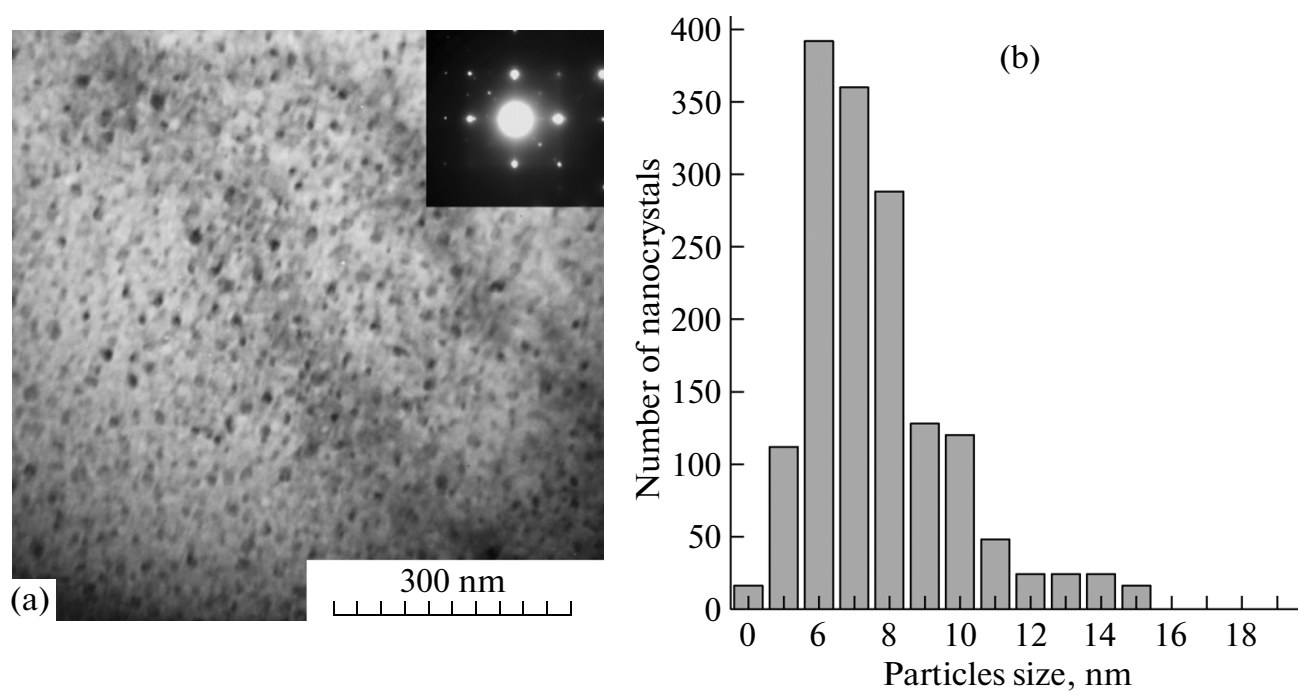

Fig. 1. (a) Bright-field TEM micrograph of the silicon surface with InAs nanoclusters and (b) nanocluster size distribution. The insert in panel "a" shows the electron diffraction pattern.

cluster size distribution $[17,18]$, which results in a lognormal nanocluster size distribution frequently observed in experiments [11, 19]. This distribution can be represented as

$$
f_{Z N}(R=r)=\frac{1}{r \sqrt{2 \pi} \ln \sigma} \exp \left[-\frac{(\ln (r / \mu))^{2}}{2(\ln \sigma)^{2}}\right],
$$

where $R$ is the nanocluster radius, $r$ is the running variable, $\mu$ is the geometrical mean, and $\sigma$ is the geometrical standard deviation (variance) of the particle size distribution.

Experimental and theoretical studies of this problem indicate that if the temperature of an irradiated target is kept constant, the nanocluster size distribution takes its characteristic steady form within the implantation time [12,20]. This form of the nanocluster size distribution depends only on the diffusion mobility of atoms during implantation, implant solubility, and volume flux of ions [12].

Today, much attention is paid to the synthesis of III-V and II-VI semiconductor nanocrystals in $\mathrm{Si}$ and $\mathrm{SiO}_{2}$, as well as $\mathrm{Si}$ nanocrystals in $\mathrm{Si}_{\boldsymbol{\lambda}}$ and $\mathrm{Si}_{3} \mathrm{~N}_{4}$. This interest stems from the intriguing physical (primarily optical) properties of such systems. Synthesis of direct-gap III-V and II-VI semiconductors in a silicon matrix is viewed as a promising technology of new-generation silicon detectors and LEDs. Previously [21-24], we discussed experimental data for the synthesis of InAs and $\mathrm{GaSb}$ nanoclusters in $\mathrm{Si}$ and $\mathrm{SiO}_{2}$ by high-dose ion implantation and post-implantation high-temperature annealing. Elemental and structural analyses of the samples were carried out, and their optical characteristics were studied.

The aim of this work was to develop a physicomathematical model of high-dose implantation of an ion pair into silicon, experimentally study the structure and optical characteristics of silicon samples with implanted As and In atoms, and compare experimental data with simulation results.

\section{EXPERIMENTAL}

(001)Si wafers were irradiated first by As ions $\left(170 \mathrm{keV}, 3.2 \times 10^{16} \mathrm{~cm}^{-2}\right)$ and then In ions $(299 \mathrm{keV}$, $2.8 \times 10^{16} \mathrm{~cm}^{-2}$ ). To avoid amorphization due to a large amount of radiation-induced defects, the substrates were heated to $500^{\circ} \mathrm{C}$ during high-fluence implantation of heavy ions.

The implant profiles in the silicon wafers were studied by the Rutherford backscattering (RBC) of $\mathrm{He}^{+}$ions on an AN 2500 electrostatic accelerator (High Voltage Engineering Europa, Netherlands). The energy of the probing beam was $1.5 \mathrm{MeV}$. To resolve As and In peaks, RBC spectra were taken at normal (entry angle $0^{\circ}$ ) and inclined (entry angle $50^{\circ}$ ) incidence of the helium ion beam. The simulation of the RBC spectra using the RUMP program package was carried out for the two cases up to complete coincidence with experimental data. The structure of the samples was examined by transmission electron microscopy (TEM) (Hitachi H-800 200-keV transmission electron microscope) in plan-view geometry, electron diffraction, and Raman scattering. Raman spectra were taken at room temperature in backscattering geometry using a Nanofinder micro-Raman spectrometer. The spectra were excited by a laser with $\lambda_{\mathrm{exc}}=473 \mathrm{~nm}$.

\section{RESULTS AND DISCUSSION}

A TEM micrograph and an electron diffraction pattern taken of the silicon wafers exposed to arsenic and indium ions are shown in Fig. 1a. From the dif- 
Table 1. Number of precipitates that were taken into account in calculations, density and mean size of InAs clusters, and the fraction of In and As atoms combined into clusters

\begin{tabular}{l|c|c|c|c}
\hline \multicolumn{1}{c|}{ Implantation conditions } & $\begin{array}{c}\text { Number of precipitates } \\
\text { taken into account } \\
\text { in calculations }\end{array}$ & $\begin{array}{c}\text { Density of distributed } \\
\text { clusters, } \mathrm{cm}^{-1}\end{array}$ & $\begin{array}{c}\text { Cluster mean size, } \\
\mathrm{mm}\end{array}$ & $\begin{array}{c}\text { Fraction of } \\
\text { implanted impurity } \\
\text { involved in InAs } \\
\text { clustering, at } \%\end{array}$ \\
\hline $\begin{array}{l}\text { As }\left(170 \mathrm{keV}, 3.2 \times 10^{16} \mathrm{~cm}^{-2}\right), \\
\text { In }\left(250 \mathrm{keV}, 2.8 \times 10^{16} \mathrm{~cm}^{-2}\right), \\
\text { implantation temperature } 500^{\circ} \mathrm{C}\end{array}$ & 1550 & $2.87 \times 10^{11}$ & $7 \pm 0.5$ & 10 \\
\hline
\end{tabular}

fraction pattern it follows that the high-fluence implantation of arsenic and indium at $500^{\circ} \mathrm{C}$ does not cause amorphization of the implanted silicon layer. At the same time, the high-dose implantation of heavy impurities not only leads to nanoclustering but also generates secondary structural defects like microtwins. To mitigate the contrast from the structural defects, TEM micrographs were taken in inclined geometry. When the sample is inclined, the contrast from structural defects disappears, whereas the contrast from inclusions (clusters) remains unchanged. From TEM micrographs, we calculated the sheet density and mean sizes of nanoclusters immediately after implantation and also estimated the number of embedded arsenic atoms and indium that enter into clusters. The results are given in Table 1.

Assuming that clusters are spherical and the density of As and In atoms is the same as that of bulk InAs semiconductors, we showed (Table 1) that about $10 \%$ of the implant are contained in the clusters immediately after implantation under "hot" conditions.

The Raman spectra of the irradiated samples exhibit an intense band of crystalline silicon in the interval $512-520 \mathrm{~cm}^{-1}$. This confirms the above conclusion that the irradiated layer remains crystalline. Along with this band, other bands in the range 150$300 \mathrm{~cm}^{-1}$ appear in the spectrum of the irradiated samples. Figure 2 shows parts of the spectra that cover the interval $150-300 \mathrm{~nm}^{-1}$ for the silicon samples before implantation, after implantation of As ions $(170 \mathrm{keV}$, $\left.3.2 \times 10^{16} \mathrm{~cm}^{-2}\right)$ and In ions $\left(250 \mathrm{keV}, 2.8 \times 10^{16} \mathrm{~cm}^{-2}\right)$, and after post-implantation annealing.

The 2 spectrum of the irradiated sample faint bands appeared with maxima at 160, 216, 235, and $300 \mathrm{~cm}^{-1}$. The band with a maximum at $300 \mathrm{~cm}^{-1}$, which is more intense in the spectrum of the as-prepared sample, is attributed to scattering by longitudinal acoustic phonons in silicon [25]. The broad band with a maximum at $160 \mathrm{~nm}^{-1}$ appearing in the spectrum of the irradiated sample corresponds to transverse acoustic phonons in silicon and is characteristic of amorphous silicon inclusions [25]. The bands with maxima at 216 and $235 \mathrm{~nm}$, which are absent in the spectrum of the as-prepared sample, correspond to transverse optical (TO) and longitudinal optical (LO) phonons in crystalline InAs [26]. That these bands appear in the spec- trum immediately after implantation suggests that nanocrystals arise during implantation. It should be noted that the band assigned to TO phonons dominates in the Raman spectra. This leads us to conclude that InAs nanocrystals are faceted mainly by (111) planes.

After annealing, the intensity of the band at $160 \mathrm{~cm}^{-1}$ markedly drops, indicating the recovery of the crystal structure of the irradiated layer (annealing of defects). At the same time, the bands assigned to LO and TO phonons in the crystalline InAs become more intense. Hence, the formation of InAs nanocrystals continues during heat treatment.

\section{THEORETICAL MODEL}

Consider a model for calculating dopant concentration profiles at high-dose implantation. In this case, the profiles depend not only on the atomic collision kinetics but also on such processes as dopant accumulation in the target, target sputtering, dopant diffusion, atomic mixing, formation of new phases during implantation, and irradiation-induced swelling.

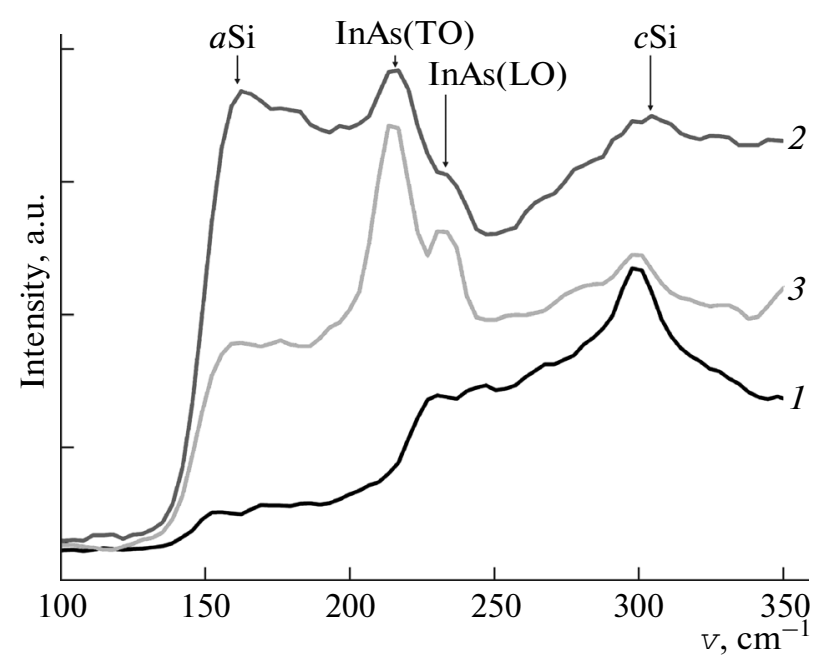

Fig. 2. Raman spectra taken of the silicon wafer (1) before and (2) after the implantation of As ions $(170 \mathrm{keV}, 3.2 \times$ $\left.10^{16} \mathrm{~cm}^{-2}\right)$ and In ions $\left(250 \mathrm{keV}, 2.8 \times 10^{16} \mathrm{~cm}^{-2}\right)$ and (3) after post-implantation annealing $\left(900^{\circ} \mathrm{C}, 60 \mathrm{~min}\right)$. 
With regard to the experimental data, we will simulate first the implantation of As $(250 \mathrm{keV}, 3.2 \times$ $\left.10^{16} \mathrm{~cm}^{-2}\right)$ and then In $\left(250 \mathrm{keV}, 2.8 \times 10^{16} \mathrm{~cm}^{-2}\right)$ into silicon at $500^{\circ} \mathrm{C}$.

If $G_{\mathrm{As}}(z, t)$ is the local rate of As atom migration at time instant $t$ at depth $z$ beneath the target surface (migration is due to the target sputtering and swelling processes), the As atom flux can be represented as follows:

$$
j_{\mathrm{As}}(z, t)=-G_{\mathrm{As}}(z, t) N_{\mathrm{As}}(z, t),
$$

where $N_{\mathrm{As}}(z, t)$ is the As atom concentration as a function of time $t$ and depth $z$. As atoms may be involved not only in sputtering- and swelling-induced mixing but also in diffusion redistribution. Therefore, it is necessary to add a diffusion flux. As a result, we have

$$
\begin{gathered}
J_{\mathrm{As}}(z, t)=-G_{\mathrm{As}}(z, t) N_{\mathrm{As}}(z, t) \\
-D_{\mathrm{As}}(z, t) \frac{\partial N_{\mathrm{As}}(z, t)}{\partial t},
\end{gathered}
$$

where $D_{\mathrm{As}}(z, t)$ is the diffusion coefficient of As atoms. It depends on depth and time, because high-dose implantation modifies the properties of the irradiated layer.

Two effects should be distinguished in considering the diffusion redistribution. The former is the concentration profile broadening because of thermal diffusion in the heated (irradiated) target. The latter is the profile broadening due to the radiation-enhanced diffusion of the implant. In our case, the latter effect prevails, since at $500^{\circ} \mathrm{C}$ the thermal diffusion coefficient is roughly equal to $5.8 \times 10^{-26} \mathrm{~cm}^{2} / \mathrm{s}$ for As and $1.6 \times$ $10^{-24} \mathrm{~cm}^{2} / \mathrm{s}$ for In [27]. At rather low temperatures (such as $500^{\circ} \mathrm{C}$ ), the diffusion during implantation is negligible; that is, the condition $\left(D_{T}(T) t\right)^{1 / 2} \ll \Delta R$ is fulfilled $\left(D_{T}\right.$ is the thermal diffusion coefficient of the dopant, $T$ is the irradiation temperature, $t$ is the irradiation time, and $\Delta R$ is the struggling of the projective, ranges of As atoms in silicon.

In the model of radiation-enhanced diffusion [2], we took into account the dependence of the dopant diffusion coefficient on the density of induced defects along the depth (in other words, on defect distribution $F_{d}(z)$ along the depth of the target) [2]. The timedependent diffusion coefficient during implantation was defined as a quantity proportional to fluence $\Phi(t)$. Thus, coefficient $D_{\mathrm{As}}(z, t)$ of radiation-enhanced diffusion takes the form

$$
D_{\text {As }}(z, t)=k \Phi(t) F_{d}(z),
$$

where $k$ is a proportionality coefficient (adjustable parameter).

Function $F_{d}(z)$ is the mean energy released in an elementary volume because of the elastic collisions of incident ions and recoil atoms with target atoms. The integral of the elastically released energy distribution over the spatial variable equals the total energy released in elastic collisions.
The distribution of the energy released in elastic collisions (or defect distribution $F_{d}$ over the depth of the target) can be constructed based on the Pearson distribution [2],

$$
F_{d}(z)=\left[10^{3} v(E) /\left(\Delta R_{P d} \sqrt{2 \pi}\right)\right] F_{d}^{P}(Z),
$$

Here, $v(E)$ is the energy released in elastic collisions (in kiloelectronvolts), $\Delta R_{p d}$ is the rms spread of the energy released in elastic collisions over the distribution depth (in nanometers), $F_{d}^{P}(Z)$ is the Pearson distribution corresponding to the symmetry of the released energy profile, $Z=\left(z-R_{p d}\right) / \Delta R_{p d}$, $z$ is the depth (in nanometers), and $R_{p d}$ is the mean depth of the spatial distribution of the energy released in elastic collisions. Quantity $F_{d}(z)$ is expressed in electronvolts per nanometer.

The local rate of sputtering- and swelling-induced As atom migration entering into formula (2) has the form [28]

$$
G_{\mathrm{As}}(z, t)=J_{\mathrm{As}} Y(t)-V_{\mathrm{As}}^{i} \int_{0}^{z} \frac{\partial}{\partial t}\left[N_{\mathrm{As}}(z, t)\right] d z,
$$

where $J_{\mathrm{As}}$ is the As ion current density, $Y$ is a function describing sputtering and depending on the surface properties of the target, and $V_{\mathrm{As}}^{i}$ is the volume of an interstitial.

Assuming that the composition of the subsurface layer of the target varies insignificantly during implantation, one can consider $Y(t)$ a constant and use the expression [29]

$$
Y=S_{\mathrm{As}} V_{t},
$$

where $V_{t}$ is the volume occupied by an atom in the nonirradiated target and $S_{\mathrm{As}}$ is the surface sputtering coefficient.

The second term in (5) describes radiation swelling. If the implant distribution changes insignificantly upon implantation (for example, when diffusion coefficient $D_{\mathrm{As}}(z, t)$ is small), one can make use of the approximation

$$
\frac{\partial}{\partial t}\left(N_{\mathrm{As}}(z, t)\right) \approx f_{\mathrm{As}}^{i}(z, t),
$$

where $f_{\mathrm{As}}^{i}(z, t)$ is the distribution function of ions implanted in the neighborhood of point $z$ at time instant $t$.

Function $G(z, t)$ is universal. It makes it possible to describe processes in which the atom redistribution during and after implantation plays a critical role (such as high-temperature implantation and annealing). Applying the law of conservation of matter to As atoms, we come to an equation for As implantation,

$$
\frac{\partial N_{\mathrm{As}}}{\partial t}=-\frac{\partial j_{\mathrm{As}}}{\partial z}+f_{\mathrm{As}}(z, t) \text {. }
$$

Here, function 


$$
f_{\mathrm{As}}(z, t)=f_{\mathrm{As}}^{i}(z, t) .
$$

plays the role of a source of free atoms (i.e., atoms not producing chemical bonds with the surface).

Thus, the equation to simulate the high-dose implantation of As into Si has the form

$$
\begin{gathered}
\frac{\partial N_{\mathrm{As}}(Z, t)}{\partial t}=\frac{\partial}{\partial z}\left[G_{\mathrm{As}}(z, t) N_{\mathrm{As}}(z, t)\right. \\
\left.+D_{\mathrm{As}}(z, t) \frac{\partial N_{\mathrm{As}}(z, t)}{\partial z}\right]+f_{\mathrm{As}}^{i}(z, t) .
\end{gathered}
$$

Below, we will consider a model of In implantation into $\mathrm{Si}$.

In our experiment, we synthesized InAs nanoclusters by high-dose implantation of As and In ions into silicon at $500^{\circ} \mathrm{C}$. Since implanted In atoms having combined with As atoms differ in properties from those not having produced a chemical bond, the fluxes of both species will be considered separately. Obviously, the flux of bound In atoms relative to the target under irradiation is set by their migration due to radiation-induced sputtering and swelling because of the continuing implantation of the dopants. If $G_{\text {In }}(z, t)$ is the local rate of migration of In atoms bonded to As atoms at time instant $t$ at depth $z$ beneath the target surface (migration is due to the target sputtering and swelling), the In atom flux can be represented as follows:

$$
j_{\mathrm{In}}(z, t)=-G_{\mathrm{In}}(z, t) n_{\mathrm{In}}(z, t),
$$

where $n_{\mathrm{In}}(z, t)$ is the concentration of In atoms bonded to As atoms as a function of time $t$ and depth $z$.

Unreacted In atoms may be involved not only in sputtering- and swelling-induced mixing but also in diffusion redistribution of the dopant. As a result, we have

$$
\begin{gathered}
J_{\mathrm{In}}(z, t)=-G_{\mathrm{In}}(z, t) N_{\mathrm{In}}(z, t) \\
-D_{\mathrm{In}}(z, t) \frac{\partial N_{\mathrm{In}}(z, t)}{\partial t},
\end{gathered}
$$

where $N_{\text {In }}(z, t)$ is the concentration of unbound In atoms implanted to depth $z$ by time instant $t$ and $D_{\mathrm{In}}(z, t)$ is the diffusion coefficient of these atoms, which is time- and depth-dependent, because the properties of the irradiated layer vary at high-dose implantation.

By analogy with expression (5), the local rate of sputtering- and swelling-induced dopant migration entering into formulas (11) and (12) has the form [28]

$$
G_{\text {In }}(z, t)=J_{\text {In }} Y(t)-V_{\text {In }}^{i} \int_{0}^{z} \frac{\partial}{\partial t}\left[N_{\text {In }}(z, t)+n_{\text {In }}(z, t)\right] d z .(
$$

Our calculations with the $A M 2 H \mathrm{H}_{\alpha}$ program package [30] show that during the aggregate implantation of As $\left(170 \mathrm{keV}, 3.2 \times 10^{16} \mathrm{~cm}^{-2}\right)$ and In $(250 \mathrm{keV}, 2.8 \times$ $10^{16} \mathrm{~cm}^{-2}$ ), thickness $d_{1}$ of the sputtered target layer equals $18.83 \mathrm{~nm}$. Target swelling $d_{2}$ due to embedded As and In atoms equals $1.27 \mathrm{~nm}$; therefore, the effect of swelling in expressions (5) and (13) can be ignored. Applying the law of conservation of matter to In atoms, we come to equations for In implantation,

$$
\begin{aligned}
& \frac{\partial N_{\mathrm{In}}}{\partial t}=-\frac{\partial j_{\mathrm{In}}}{\partial z}+f_{\mathrm{In}}(z, t), \\
& \frac{\partial n_{\mathrm{In}}}{\partial t}=-\frac{\partial j_{\mathrm{In}}}{\partial z}+f_{\mathrm{In}}^{n}(z, t) .
\end{aligned}
$$

Here, function

$$
f_{\mathrm{In}}(z, t)=f_{\mathrm{In}}^{i}(z, t)-f_{\mathrm{In}}^{i}(z, t),
$$

plays the role of a source of free In atoms and function $f_{\mathrm{In}}^{r}(z, t)$ is a function numerically equal to the number of In atoms having combined with previously implanted As atoms in a unit volume per unit time.

According to the theory of chemical reactions, function $f_{\mathrm{In}}^{*}(z, t)$ is proportional to the concentration of reactants. Therefore, one can write

$$
f_{\mathrm{In}}^{r}(z, t)=K^{r} N_{\mathrm{As}}^{t}(z, t) N_{\mathrm{In}}(z, t),
$$

where $N_{\mathrm{As}}^{t}$ is the concentration of As atoms not combined with In atoms, $K^{r}$ is a coefficient characterizing the formation rate of InAs nanoclusters and depending on the types of dopants and implantation-induced defects

Since bound impurity atoms arise in the reaction described above, we obtain an expression for the function of a bound atom source in Eq. (14),

$$
f_{\mathrm{In}}^{n}(z, t)=f_{\mathrm{In}}^{r}(z, t)
$$

As a distribution function for atoms having stopped at point $z$ per unit time $t$, we took Pearson type IV distribution $F^{P}(z)$ both for arsenic, $f_{\mathrm{As}}^{i}(z, d)$, and for indium, $f_{\mathrm{In}}^{i}(z, t)[2]$,

$$
f_{\mathrm{As}, \mathrm{In}}^{i}(z, t)=J F^{P}(z) .
$$

Now we can write a set of equations to simulate the high-dose implantation of In ions into silicon that was preimplanted by As ions,

$$
\begin{aligned}
\frac{\partial N_{\mathrm{In}}(z, t)}{\partial t}=[ & \left.G_{\mathrm{In}}(z, t) N_{\mathrm{In}}(z, t)+D_{\mathrm{In}}(z, t) \frac{\partial N_{\mathrm{In}}(z, t)}{\partial z}\right] \\
& +f_{\mathrm{In}}^{i}(z, t)-f_{\mathrm{In}}^{r}(z, t) \\
\frac{\partial n_{\mathrm{In}}(z, t)}{\partial t}= & \frac{\partial}{\partial z}\left[G_{\mathrm{In}}(z, t) n_{\mathrm{In}}(z, t)\right]+f_{\mathrm{In}}^{*}(z, t) .
\end{aligned}
$$

Equations (10), (19), and (20) constitute a set of convection-diffusion-reaction equations. Such a model is a basic model [4] among those used to describe the impurity redistribution at relatively high integral implantation doses.

The mathematical model of As and In ion implantation into silicon is based on solving nonlinear diffusion kinetic equations (10), (19), and (20). 
Table 2. Simulation parameters

\begin{tabular}{l|c|c}
\hline \multicolumn{1}{c|}{ Parameters } & As & In \\
\hline $\begin{array}{l}\text { Atomic concentration in target }- \\
N_{\mathrm{Si}} \text { at } / \mathrm{cm}^{3}\end{array}$ & $5 \times 10^{22}$ & $5 \times 10^{22}$ \\
Ion energy $-E, \mathrm{keV}$ & 170 & 250 \\
Ion current density $-J, \mu \mathrm{A} / \mathrm{cm}^{2}$ & 2 & 2 \\
Fluence $-\Phi$, ion $/ \mathrm{cm}^{2}$ & $3.2 \times 10^{16}$ & $2.8 \times 10^{16}$ \\
Ion projective range $-R_{p}, \mathrm{~nm}$ & 100 & 107 \\
Longitudinal straggling $-\Delta R_{p}, \mathrm{~nm}$ & 34.6 & 36.0 \\
Profile skewness $-S k$ & 0.23 & 0.21 \\
$\begin{array}{l}\text { Energy released in elastic collisions }- \\
v(E), \text { keV }\end{array}$ & 130.7 & 95.7 \\
$\begin{array}{l}\text { Mean depth of spatial distribution of } \\
\text { energy released in elastic collisions }-\end{array}$ & 74.4 & 54.2 \\
$R_{P d}$, nm & & \\
$\begin{array}{l}\text { Longitudinal struggling of spatial dis- } \\
\text { tribution of energy release in elastic }\end{array}$ & 42.7 & 35.8 \\
eollision ${ }_{\alpha}-\Delta R_{P d}$, nm & & \\
$\begin{array}{l}\text { Skewness of depth distribution of } \\
\text { energy released in elastic collisions }-\end{array}$ & 0.55 & 0.7 \\
$S k_{d}$ & & \\
$\begin{array}{l}\text { Target sputtering ratio }-S \\
\text { Rate of impurity migration through } \\
\text { the target surface }-K^{s}, \text { cm/s }\end{array}$ & $1.3 \times 10^{-8}$ & $1 \times 10^{-8}$ \\
\hline
\end{tabular}

The respective initial and boundary conditions for a semi-infinite plane target have the form

$$
\begin{aligned}
N_{\text {As }}(z, t=0) & =0, \quad N_{\text {As }}(\infty, t)=0 . \\
n_{\text {In }}(z, t=0) & =N_{\text {In }}(z, t=0)=0, \\
n_{\text {In }}(\infty, t) & =N_{\text {In }}(\infty, t)=0 .
\end{aligned}
$$

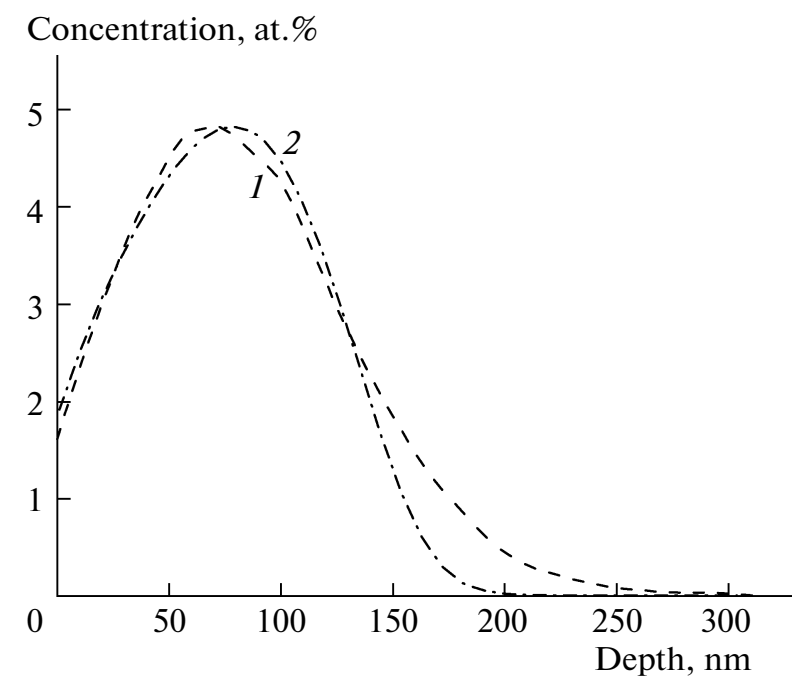

Fig. 3. Depth profiling of arsenic atoms in silicon: (1) experiment and (2) calculation.
The diffusion of impurity through the surface of the target is embodied in the boundary condition

$$
D_{\mathrm{As}, \text { In }} \frac{\partial N_{\mathrm{As}, \text { In }}(0, t)}{d z}=K_{\mathrm{As}, \text { In }}^{s} N_{\mathrm{As}, \text { In }}(0, t),
$$

where $K_{\mathrm{As} \text {, In }}^{s}$ is the rate of migration of a given impurity through the surface of the target. It was assumed here that bound impurity does not taken part in diffusion.

When simulating the distribution profiles of arsenic and indium implanted into silicon, we used in the program package the parameter values listed in Table 2. Here, $E, J$, and $\Phi$ are conditions for implantation of As and In into the Si target and $R_{p}, \Delta R_{p}, S k, v(E), R_{p d}$, $\Delta R_{p d}$, and $S k_{d}$ are the spatial moments of the implant distribution and energy released in elastic collisions. These parameters were determined by solving the backward kinetic equation [2]. Sputtering ratio $S$ of the target was calculated with the TRIM program [1], and adjustable parameter $K_{\mathrm{As} \text {, In }}^{s}$ (rate of migration of a given impurity through the surface of the target) was taken so as to provide the best agreement between experimental data and simulated profiles.

\section{THEORETICAL RESULTS VERSUS EXPERIMENTAL DATA}

The physicomathematical model of the high-dose implantation of As and In ions into silicon is based on numerically solving the set of convection-diffusionreaction equations (10), (19), and (20). Let us discuss characteristic processes attendant on the high-dose implantation of As and In comparing theoretical and experimental results. In numerical calculations, it is necessary to properly select the diffusion coefficient and the rate of the chemical reaction (synthesis of InAs nanoclusters in silicon) and also properly set boundary conditions at the surface. These parameters were estimated in the experiments on high-dose implantation of As and In into silicon.

Figure 3 shows the calculated and experimental concentration distributions of arsenic ions implanted into silicon with energy $E=170 \mathrm{keV}$ and fluence $\Phi=$ $3.2 \times 10^{16} \mathrm{~cm}^{-2}$. It is seen that the profile simulated in terms of this model fits the experimental one well. This agreement was achieved for average diffusion coefficient $D_{\mathrm{As}}=2.68 \times 10^{-16} \mathrm{~cm}^{2} / \mathrm{s}$. The diffusion coefficient was averaged over spatial variable $z$ from the surface to a depth of $3 R_{p}$. Such a high arsenic atom diffusion coefficient at the given implantation temperature can be explained by the fact that diffusion is substantially influenced by nonequilibrium defects having arisen in a large amount implantation. A discrepancy between the As profiles in the tail of the distribution (i.e., at a low concentration) can be explained by a more complicated dependence of the diffusion coefficient on fluence $\Phi(t)$ and on defect distribution $F_{d}(z)$ over the depth of the target (see formula (3)). For bet- 
Concentration, at. $\%$

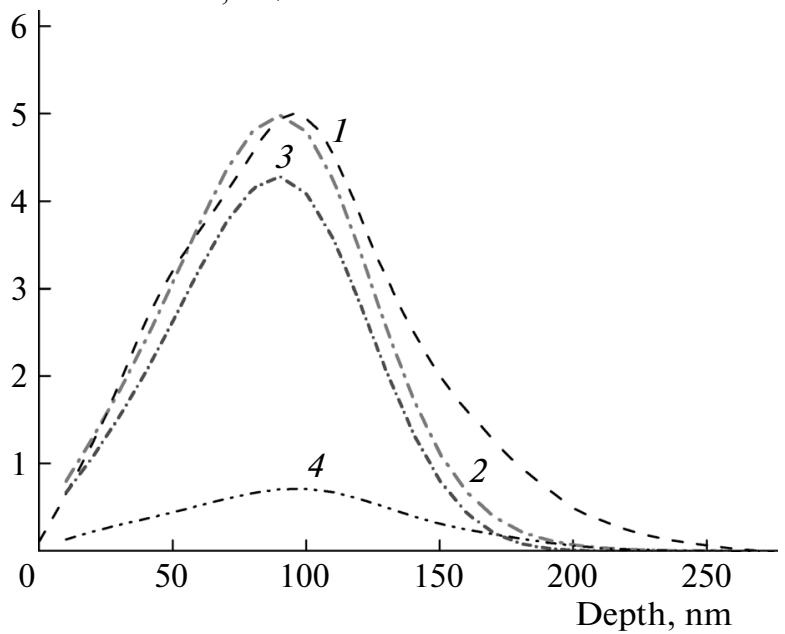

Fig. 4. Depth profiling of indium atoms in silicon: (1) experiment, (2) calculated total concentration of indium atoms in silicon, (3) indium atoms not combined with arsenic atoms (calculation), and (4) indium atoms combined with arsenic atoms, i.e., entering into InAs nanoclusters (calculation).

ter agreement between the experimental and simulated implant distributions, it is necessary to take a larger (than in [1] or [2]) positive value of skewness $S k$ in calculating the Pearson IV distribution at the given energy of incident ions.

Figure 4 plots the simulated and experimental concentration profiles of indium implanted with energy $E=250 \mathrm{keV}$ and fluence $\Phi=2.8 \times 10^{16} \mathrm{~cm}^{-2}$ into arsenic-preimplanted $(E=170 \mathrm{keV}, \Phi=3.2 \times$ $10^{16} \mathrm{~cm}^{-2}$ ) silicon. It is seen that some of the indium atoms (about $10 \%$ ) implanted at $500^{\circ} \mathrm{C}$ combine with preimplanted arsenic, that is, produce crystalline InAs nanoclusters. When calculating the depth distribution of the implanted indium, this fact was embodied in Eqs. (14)-(17). The fraction of indium atoms bonded to arsenic atoms is presented by curve 4 in Fig. 4 .

Note that both diffusion coefficient $D_{\text {In }}$ and coefficient $K^{r}$ (characterizing the formation rate of InAs nanoclusters) are unknowns in simulating the implantation of indium into silicon, i.e., in solving Eqs. (19)-(23). With this in mind, we proceeded as follows. The value of indium atom diffusion coefficient $D_{\mathrm{I}}$ was determined from the best agreement between the experimental and simulated profiles (by analogy with arsenic atoms; i.e., the influence of the preimplanted arsenic on the indium diffusion was ignored). To this end, we solved Eq. (10) but for indium (not for arsenic) and then solved Eqs. (19)(23) with the indium diffusion coefficient known $\left(D_{\text {In }}=7.56 \times 10^{-16} \mathrm{~cm}^{-2}\right)$. Having solved these equations, we found the value of adjustable coefficient $K^{r}$ : $K^{r}=1.5 \times 10^{-24} \mathrm{~cm}^{3} / \mathrm{s}$.
The integral losses of the impurities intersecting the target at the implantation of As $\left(170 \mathrm{keV}, 3.2 \times 10^{16} \mathrm{~cm}^{-2}\right)$ and In $\left(250 \mathrm{keV}, 2.8 \times 10^{16} \mathrm{~cm}^{-2}\right)$ into silicon at $500^{\circ} \mathrm{C}$ are, respectively, $5 \%$ and $4 \%$. This effect, the diffusion flux of impurities through the opposite boundary, was taken into account by setting $K^{r}$ equal to $K_{\mathrm{As}}^{s}=1.3 \times$ $10^{-9} \mathrm{~cm} / \mathrm{s}$ and $K_{\mathrm{In}}^{\mathrm{s}}=1 \times 10^{-9} \mathrm{~cm} / \mathrm{s}$.

\section{CONCLUSIONS}

Using TEM and Raman spectroscopy, it was found that the implantation of As $\left(170 \mathrm{keV}, 3.2 \times 10^{16} \mathrm{~cm}^{-2}\right)$ and In $\left(250 \mathrm{keV}, 2.8 \times 10^{16} \mathrm{~cm}^{-2}\right)$ into silicon at $500^{\circ} \mathrm{C}$ leads to the formation of InAs nanoclusters, which have a mean diameter of $7 \mathrm{~nm}$ and are distributed with a density of $2.87 \times 10^{11} \mathrm{~cm}^{-2}$.

A physicomathematical model and dedicated software were developed to simulate the high-dose implantation of arsenic and indium into silicon. They take into account such processes as radiationenhanced diffusion, sputtering and swelling of the target, and formation of a new phase. The dependence of the diffusion coefficient on the depth distribution of defects caused by the implantation of As and In impurities is also included in the model. In terms of the model, the depth profiling of the impurity (both in a free state and in nanoclusters) was made.

From theoretical and experimental data, the mean values of the radiation-enhanced diffusion coefficients for indium $\left(D_{\mathrm{In}}=7.56 \times 10^{-16} \mathrm{~cm}^{2} / \mathrm{s}\right)$ and arsenic $\left(D_{\mathrm{As}}=2.68 \times 10^{-16} \mathrm{~cm}^{2} / \mathrm{s}\right)$ in silicon were determined. The developed model and software make it possible not only to find the mean coefficients of radiationenhanced diffusion of impurities in silicon but also determine the fraction of bound impurity, i.e., impurity entering into InAs nanoclusters. We are planning to consider a theory of formation and reconstruction of binary semiconductor nanoclusters in silicon and $\mathrm{SiO}_{2}$ after post-implantation heat treatment. In this case, the concentration profiles of the unbound implant and the implant entering into nanoclusters will serve as input data.

\section{ACKNOWLEDGMENTS}

This work was supported by the Belarussian Republic Foundation for Basic Research, grant nos. F13AZ-010, F14KAZ-003, and T14KAZ-002.

\section{REFERENCES}

1. J. F. Ziegler, J. P. Biersack, and U. Littmark, The Stopping and Range of Ions in Solids (Pergamon, New York, 1985); J. F. Ziegler and P. Biersack, SRIM: The Stopping and Range of Ions in Matter, Version 96.07 (IBMResearch, Yorktown, 1996).

2. A. F. Burenkov, F. F. Komarov, M. A. Kumakhov, and M. M. Temkin, Tables of Ion Implantation Spatial Dis-

\section{$\begin{array}{llll}\text { TECHNICAL PHYSICS Vol. } 60 & \text { No. } 9 & 2015\end{array}$}


tributions (Gordon and Breach, New York-LondonParis, 1986).

3. A. M. Yacout, N. G. Lam, and J. F. Stubbins, Nucl. Instrum. Methods Phys. Res. B 59-60, 567 (1991).

4. A. F. Komarov, "Processes of ion and electron interaction with solids under high-dose and high-energy radiation," Doctoral Dissertation in Mathematical Physies, (Minsk, 2005).

5. F. F. Komarov and A. F. Komarov, Physical Processes on Ion Implantation in Solid (UP Tekhno-Print, Minsk, 2001).

6. W. Moller, W. Eckstein, and J. P. Biersack, Comput. Phys. Commun. 51, 355 (1988).

7. A. Schonborn, N. Hecking, and E. H. Kaat, Nucl. Instrum. Methods Phys. Res. B 43, 170 (1989).

8. E. B. Boiko, F. F. Komarov, A. F. Komarov, et al., Zh. Tekh. Fiz. 64 (6), 106 (1994).

9. F. F. Komarov, A. F. Komarov, and A. S. Petrov, Mikroelektronika 31, 361 (2002).

10. P. Zukowski, Cz. Karwat, F. F. Komarov, A. F. Komarov, et. al., Phys. Status Solidi 157, 373 (1996).

11. G. Mattei, P. Mazzoldi, and H. Bernas, Materials Science with Ion Beams, Ed. by H. Bernas (Springer, Berlin-Heidelberg, 2010), pp. 287-316.

12. C. W. Yuan, C. N. Boswell, S. J. Shin, C. Y. Ziao, J. Guzman, J. W. Ager III, E. E. Haller, and V. C. Chrzan, Appl. Phys. Lett. 95, 083120 (2005).

13. Y. Ramaswamy, T. E. Haynes, C. W. White, W. J. Moberlychan, S. Roorda, and M. J. Aziz, Nano. Lett. 5, 373 (2005).

14. Y. Yang, Ch. Zhang, Y. Song, J. Gou, Z. Zhang, Y. Meng, H. Zhang, and Y. Ma, Nucl. Instrum. Methods Phys. Res. B 308, 24 (2013).

15. A. V. Krasheninnikov and K. Norlund, J. Appl. Phys. 107, 071301 (2010).

16. I. Lifshitz and V. Slyozov, J. Phys. Chem. Solids 19, 35 (1961).
17. C. Wagner, Z. Electrochem. 65, 581 (1961).

18. H. Bernas, Nucl. Instrum. Methods Phys. Res. B 268, 3171 (2010).

19. R. E. Lamaestra and H. Bernas, Phys. Rev. B 73, 125317 (2003).

20. C. W. Yuan, D. O. Yi, I. D. Sharp, S. J. Shin, C. Y. Liao, J. Guzman, J. W. Ager III, E. E. Haller, and D. C. Chrzan, Phys. Rev. Lett. 102, 146101 (2009).

21. F. Komarov, L. Vlasukova, W. Wesch, A. Komarov, O. Milchanin, S. Grechnyi, A. Mudryi, and A. Ivaniukovich, Nucl. Instrum. Methods Phys. Res. B 266, 3557 (2008).

22. F. Komarov, L. Vlasukova, O. Milchanin, A. Mudry, B. Dunets, W. Wesch, and E. Wendler, Phys. Status Solidi A 209, 148 (2011).

23. F. Komarov, L. Vlasukova, O. Milchanin, W. Wesch, E. Wendler, J. Zuk, and I. Parkhomenko, Mater. Sci. Eng., B 178, 1169 (2013).

24. F. Komarov, L. Vlasukova, M. Greben, O. Milchanin, J. Zuk, W. Wesch, E. Wendler, and A. Togambaeva, Nucl. Instrum. Methods Phys. Res. B 307, 102 (2013).

25. M. H. Brodsky, M. Cardona, and J. J. Cuona, Phys. Rev. B 16, 3556 (1977).

26. M. Landolt and J. Bornstein, Numerical Data and Functional Relationships in Science and Technology (Springer, Berlin-Heidelberg, 1982).

27. F. F. Komarov, A. P. Novikov, and A. F. Burenkov, Ion Implantation (Belarussk. Gos. Univ., Minsk, 1994).

28. H. U. Jager, E. Hensel, U. Kreissig, W. Skorupa, and E. Sobeslavsky, Thin Solid Films 127, 159 (1985).

29. R. Behrisch, Sputtering by Particle Bombardment (Springer, Berlin, 1981).

30. A. F. Komarov, F. F. Komarov, P. Zukovski, Cz. Karwat, and A. A. Kamarou, Vacuum 63, 495 (2001).

Translated by V. Isaakyan

\section{SPELL OK}

